\title{
Anthós
}

\section{An Analysis of the Reactivation Potential of a Deep- seated Landslide in the Oregon Coast Range under varying Hydrologic conditions with Seismic Triggering}

Emily E. Smoot

Portland State University

Follow this and additional works at: https://pdxscholar.library.pdx.edu/anthos

Part of the Geology Commons, Geomorphology Commons, and the Geophysics and Seismology Commons

Let us know how access to this document benefits you.

\section{Recommended Citation}

Smoot, Emily E. (2020) "An Analysis of the Reactivation Potential of a Deep-seated Landslide in the Oregon Coast Range under varying Hydrologic conditions with Seismic Triggering," Anthós: Vol. 9: Iss. 1, Article 7.

https://doi.org/10.15760/anthos.2020.9.1.7

This open access Article is distributed under the terms of the Creative Commons Attribution-NonCommercialShareAlike 4.0 International License (CC BY-NC-SA 4.0). All documents in PDXScholar should meet accessibility standards. If we can make this document more accessible to you, contact our team. 


\title{
An Analysis of the Reactivation Potential of a Deep-seated Landslide in the Oregon Coast Range under varying Hydrologic conditions with Seismic Triggering
}

\author{
Emily E Smoot
}

\section{Introduction}

The mass movement of earth can occur in several ways and in many locations across the world. Isolated events can be caused by increased precipitation, while failures can be due to seismic activity. The destruction produced by a mass movement of earth can be devastating to populations that are nearby. Landslide events are also "more likely to occur where previous failures are already present" (Mirus, Smith \& Baum, 2017). These events can also greatly alter the hydrologic processes in an area (Mirus, Smith \& Baum, 2017). The changes that may occur with the reactivation of a landslide can promote the surface to remain unstable, as the hydrologic processes change, thus promoting more failures along the already exposed slope (Mirus, Smith \& Baum, 2017). Similarly, earth movement induced by seismic activity has an initial failure and can experience a second failure after the seismic activity has ceased (Di et al., 2016). These landslides can be rapid and travel long distances away from the source area (Di et al., 2016).

The remobilization of landslides is nothing to be taken lightly, as "the deadliest landslides in recent U.S. history resulted from reactivation of existing landslides" (Mirus, Smith \& Baum, 2017). Studying the potential for reactivation of landslides can benefit an entire community, as it could provide life-saving information and greater detail about the hazards of being near previously failed slopes.

\footnotetext{
* The author would like to express their gratitude to Dr. Adam Booth for his guidance during this project, to their fellow peers in the course that aided in field data collections, and and to Genna McLeod for helping edit the article for publication
} 
The focus of this study will be on the reactivation potential of a deepseated landslide located in the Coast Range of Oregon. For the study area, a detailed map of the landslide features was made using field observations and Lidar images. Field observations were used to generate a cross-section of the original deposit. This cross-section was then used to help determine what it would take to remobilize the deep-seated landslide.

\section{Field Site}

The field site for this study was in the Tillamook State Forest, a densely wooded area with abundant vegetation. The climate of the area is that of a temperate rainforest. The headscarp of the deep-seated landslide is near the NW Cochran Road, and the toe of the landslide flowed into the Nehalem River (Figure 1).

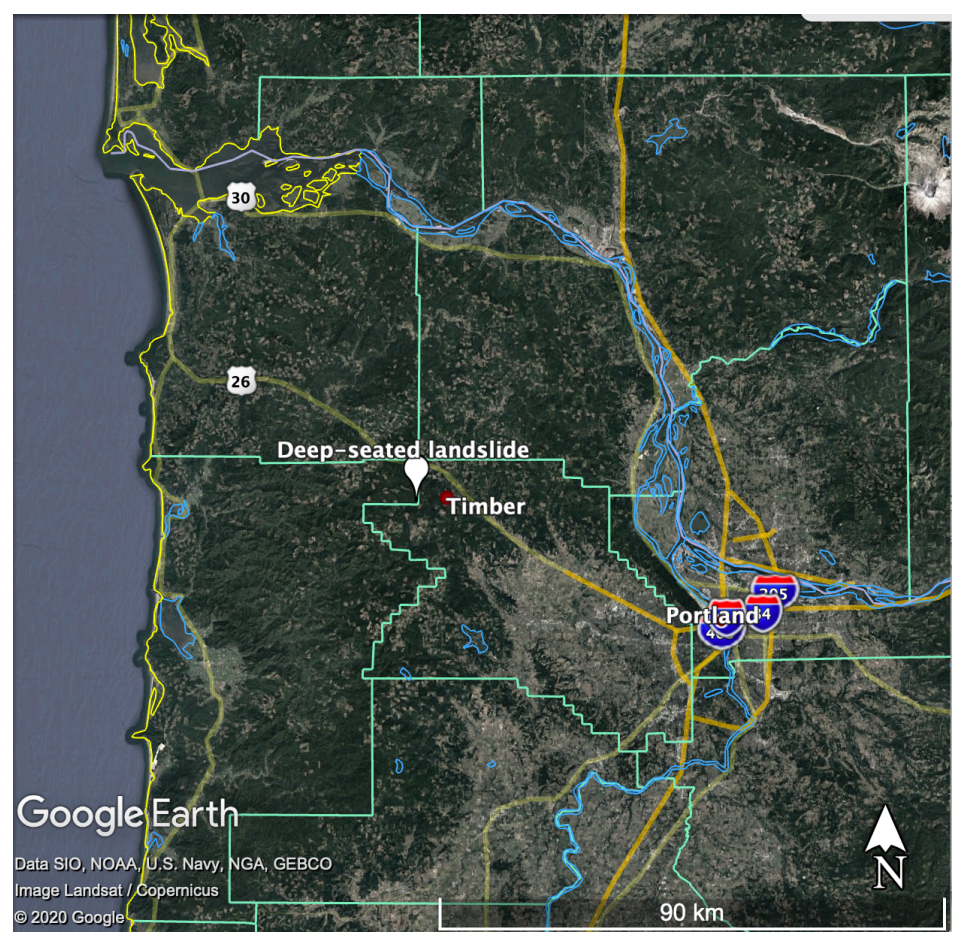

Figure 1. A map image of the field site located in Tillamook State Forest, with Timber marked as a reference point (Google Earth, 2020). 
The field site is in a formation made up of predominantly volcanic and sedimentary rocks (Figure 2). Since the study was conducted in the winter, the survey area was thoroughly covered with eight to eighteen inches of snow.

\section{Oregon Coast Range}

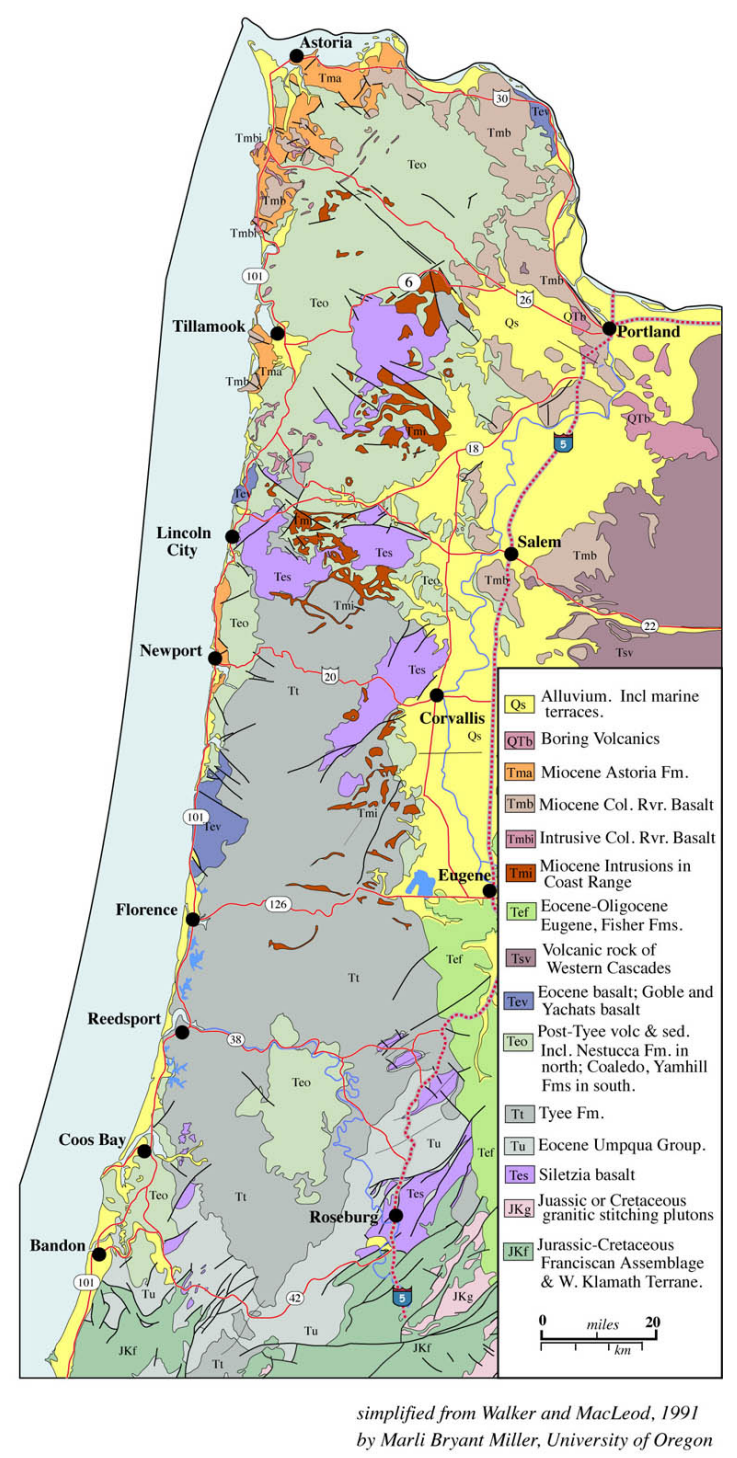

Figure 2. A map of the rock formations that compose the coast of Oregon.

Referenced from Marlimillerphoto.com

(https://www.marlimillerphoto.com/ORCoastR.html, Accessed 2019). 


\section{Methods}

The purpose of this study was to map a deep-seated landslide as well as determine the criteria for the landslide to become reactivated and fail a second time. To produce the map of the landslide features, a Lidar image was printed and taken into the field and used to take note of features present that may not necessarily show themselves in a digital elevation model (DEM). For example, the presence of water at the surface or running in gullies. Once field observations were made, a final map was constructed using the same Lidar DEM in ArcMap, using notes and other software tools to most accurately capture the surface morphology of the landslide.

For the second part of the study, the field data collected was a profile of the deposit. This profile was measured using an inclinometer and a tape measure. The field measurements taken were then used to create a field generated crosssection of the landslide in Excel. To complete any further calculations, the water table underneath the landslide was estimated. The weather and snow cover did not aid in displaying any ponded water in the closed depressions found, so the water table was estimated by making a profile of a gully, which is known to have flowing water in the area. The water table profile was translated onto the crosssection by corresponding distance from the river to relative elevation. This field developed cross-section with the water table was then used as a base for the factor of safety calculations computed for the slope. The method used to calculate the factor of safety of the deposit was the Swedish method of slices. This method breaks the field developed cross-section into two-dimensional planes, or slices, and then factors of safety are computed for each slice using the following equation:

$$
F_{s}=\frac{C+\left(\gamma_{s} H-\gamma_{w} h\right) \cos ^{2}(\theta) \tan (\varphi)}{\gamma_{s} H \sin (\theta) \cos (\theta)}
$$


In equation (1), $F_{S}$ is the factor of safety for a slice, $C$ is cohesion, $\gamma_{S}$ is the unit weight of the soil, $H$ is the soil depth, $\gamma_{w}$ is the unit weight of water, $h$ is the height of the water table, $\theta$ is the slope angle and $\varphi$ is the internal friction angle of the material. Once the individual factors of safety are calculated, the resisting forces are summed and then divided by the sum of the driving forces.

$$
F=\frac{\sum M_{r}}{\sum M_{d}}
$$

Where $F$ is the factor of safety of the landslide, $M_{r}$ is the resisting moment, and $M_{d}$ is the driving moment (2). This approximates a landslide deposit's entire factor of safety and informs one about which section of the landslide is acting to push or hold the deposit on to the slope. Computations for equations (1) and (2) were done in an Excel spreadsheet made by John R. Greenwood. The factor of safety was computed for base conditions, conditions that were directly measured in the field, or from the Lidar data, and the factor of safety was computed estimating what conditions would be if the water table were fully saturated. A fully saturated water table was estimated by assuming that the degree of saturation was equal to one, and thus the water table height was equal to that of the ground surface.

The second analysis done was to determine the critical acceleration for both conditions. The critical acceleration was calculated using Newmark's analysis for a "rigid-plastic block sliding on an inclined plane" (Jibson, 1993). The critical acceleration is the threshold for which any acceleration below this number does not cause permanent displacement within the slope (Jibson, 1993). The critical acceleration is reported as a percentage of gravity.

$$
\frac{a_{c}}{g}=(F-1) \sin \left(\theta_{\text {avg }}\right)
$$


In equation (3), $a_{c}$ is critical acceleration, $F$ is the factor of safety for the landslide, $g$ is gravitational acceleration, and $\theta_{\text {avg }}$ is the average slope of the landslide (Jibson, 1993). After the critical acceleration was calculated for both situations, the corresponding Modified Mercalli Intensity (MMI) that could produce this level of critical acceleration was determined. The MMI measures the intensity of the shaking the earthquake produces. The constants used in the calculations can be found in Table 1. The friction angle and cohesion used were found in a similar study and applied to the field area (Jesus et al., 2017). The density was determined based on the rock in the area. The main formations are volcanic and sedimentary. These density values were then averaged (University of Texas, Accessed 2019).

Table 1. Constants used in the calculations for the factor of safety and critical acceleration for the two conditions.

\begin{tabular}{|c|c|c|c|c|}
\hline \multicolumn{5}{|c|}{ Average } \\
\hline Rock & Internal & slope & & Water \\
\hline $\begin{array}{l}\text { Density } \\
\left(\mathrm{kg} / \mathrm{m}^{\wedge} 3\right)\end{array}$ & $\begin{array}{l}\text { Friction } \\
\text { angle }\left(^{\circ}\right)\end{array}$ & $\begin{array}{l}\text { angle } \\
\left({ }^{\circ}\right)\end{array}$ & $\begin{array}{c}\text { Cohesion } \\
(\mathrm{kPa})\end{array}$ & $\begin{array}{l}\text { Density } \\
\left(\mathrm{kg} / \mathrm{m}^{\wedge} 3\right)\end{array}$ \\
\hline 2800 & 30 & 10.7 & 10 & 1000 \\
\hline
\end{tabular}

\section{Results}

From field and Lidar observations, it was determined that the relative age of the deep-seated landslide is one that is young and inactive. As will be discussed later, there are many sharper hummocks in the deposit, and any channels or gullies forming have yet to be more deeply incised.

Table 2 presents the data collected in the field using a tape measure and an inclinometer. This data was then used to make the field developed cross-section of the study area (Figure 4). 
Table 2. Raw profile data used to generate the field developed cross-section.

\begin{tabular}{|c|c|c|}
\hline $\begin{array}{l}\text { Station } \\
\text { number }\end{array}$ & Distance (m) & Slope $\left({ }^{\circ}\right)^{1}$ \\
\hline 0 & 0 & 0 \\
\hline 1 & 5 & 8 \\
\hline 2 & 14 & 35 \\
\hline 3 & 18 & 0 \\
\hline 4 & 12 & 22 \\
\hline 5 & 10 & 2 \\
\hline 6 & 17 & 24 \\
\hline 7 & 70 & 11 \\
\hline 8 & 28 & 9 \\
\hline 9 & 29 & 3 \\
\hline 10 & 18 & -13 \\
\hline 11 & 17 & -1 \\
\hline 12 & 19.2 & 21 \\
\hline 13 & 16.3 & 27 \\
\hline 14 & 21 & 1 \\
\hline 15 & 60 & -1 \\
\hline 16 & 87 & 34 \\
\hline
\end{tabular}

The map of the surface morphology of the deep-seated landslide shows a lot of hummocky topography, which is an expected feature for large deep-seated landslide and rockslide failures, especially those in a volcanic setting or with volcanic lithology (Paguican, Wyk de Vries, \& Lagmay, 2012). The hummocks are relatively sharp and decrease in their frequency as distance away from the

${ }^{1}$ Positive slopes were slopes recorded above the observer's eye level whereas negative slopes are slopes recorded below the observer's eye level. Eyelevel is a slope of zero. 
main headscarp is increased (Paguican, Wyk de Vries, \& Lagmay, 2012). The toe of the landslide has been cut through by the Nehalem River, and there is a large internal scrap located on the western side of the landslide (Figure 3). Along with the other common features, two lineaments were marked, as the observations from the Lidar data and in the field were not enough to clarify these features.

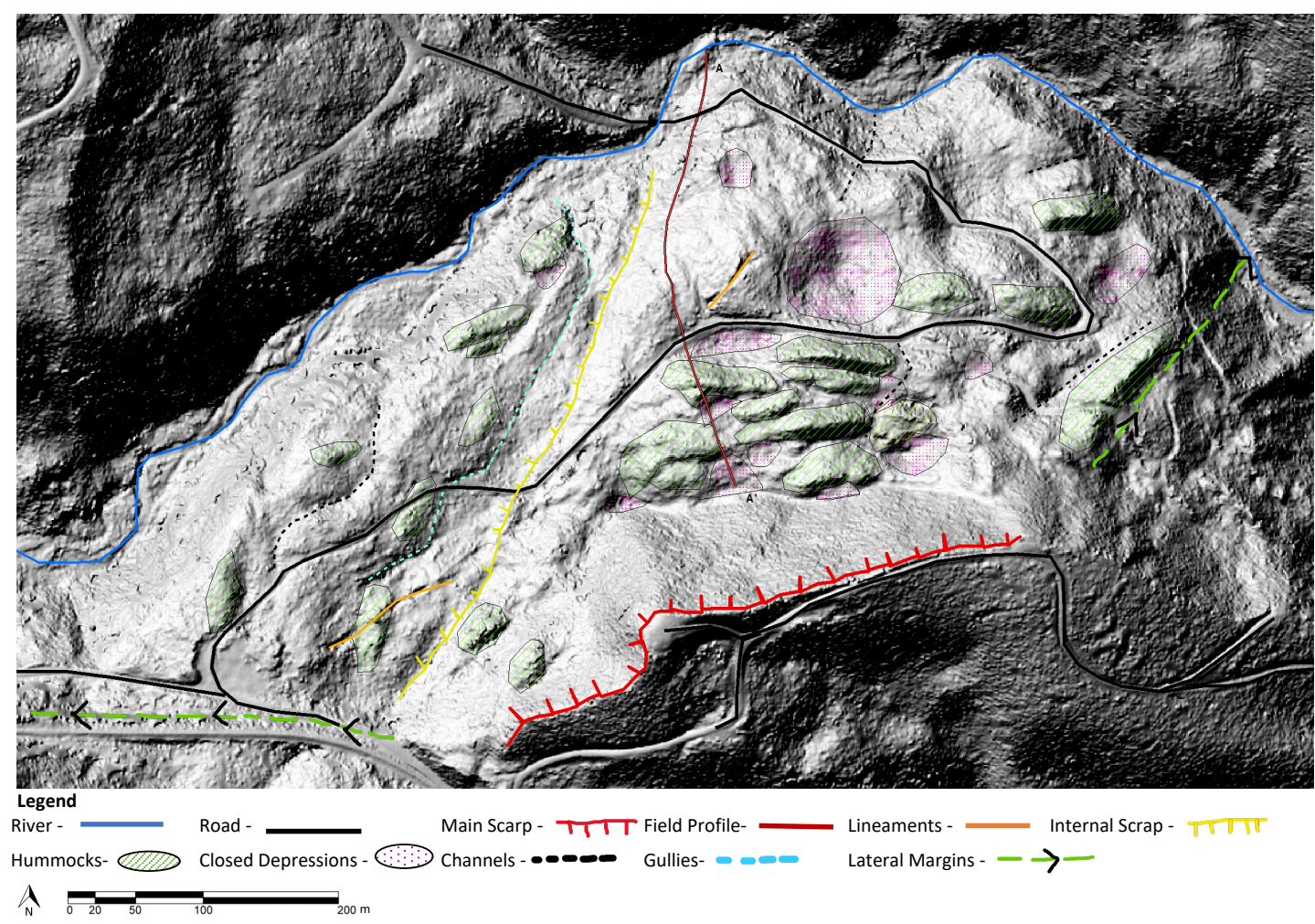

Figure 3. A map of the surface morphology features in the deep-seated landslide, based on a Lidar image of the map and field observations.

The resulting field generated cross-section, which was derived from the field collected data (Table 2), was found to have one definable hummock and a definable thrust. There are two locations in the profile that suggest the water table is at surface elevation (Figure 4). The average slope of the landslide deposit including the headscarp was calculated to be 10.7 degrees (Table 1). The potential failure plane if remobilization was to occur was determined to be circular so that 
the angle of the headscarp could be smoothly connected with the toe of the deposit (Figure 4). The slices used for the Swedish method of slices are overlaid in the cross-section. Seven slices were drawn to accurately capture the profile (Figure 4). Three of these slices are orientated against the failure plane and contribute to the resisting forces, while four of the slices contribute to the driving forces of the landslide (Figure 4).

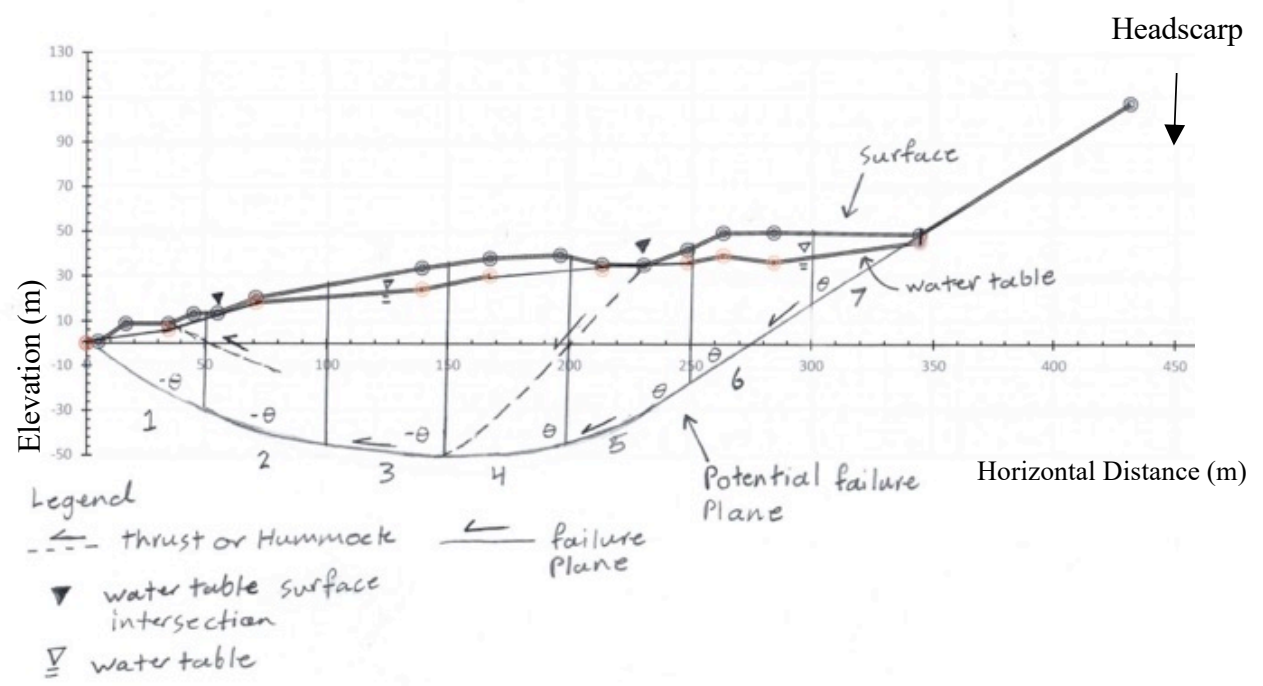

Figure 4. The field generated cross-section of the NW Cochran Road field site. The drawing includes important landscape features, labeled within the drawing. The other notations in the drawing were used in the Swedish method of slices for factor of safety: the numbering of the slices and the $\theta$ denote a positive or negative slope in relation to the potential failure plane.

The factor of safety calculated for base conditions was 2.22 , and the factor of safety calculated for saturated conditions was 1.42 (Table 3). Because both factors of safety calculated are over one, the slope is stable for both conditions. Critical acceleration for saturated condition was found to be $7.7 \%$ of g using equation (3), and $22 \%$ of $g$ for base conditions (Table 3). These critical accelerations correspond to an MMI of five or greater and seven or greater 
respectively (Table 3; Table 4). The determination of the MMI was done using Table 3.

Table 3. Taken form the United States Geological Survey and accessed 2019. A table relating peak ground acceleration to Modified Mercalli Intensities and other characteristics based on Worden (2012).

\begin{tabular}{|c|c|c|c|c|c|c|c|c|c|}
\hline $\begin{array}{c}\text { PERCEIED } \\
\text { SHAKIIG }\end{array}$ & Not felt & Weak & Light & Moderate & Strong & Very strong & Severe & Violent & Extreme \\
\hline $\begin{array}{c}\text { POTENTIAL } \\
\text { DAMAGE }\end{array}$ & none & none & none & Very light & Light & Moderate & Mod./Heavy & Heavy & Very Heavy \\
\hline PEAK ACC.(\%g) & $<0.05$ & 0.3 & 2.8 & 6.2 & 12 & 22 & 40 & 75 & $>139$ \\
\hline PEAK VEL.(cm/s) & $<\mathbf{0 . 0 2}$ & $\mathbf{0 . 1}$ & $\mathbf{1 . 4}$ & $\mathbf{4 . 7}$ & $\mathbf{9 . 6}$ & $\mathbf{2 0}$ & $\mathbf{4 1}$ & $\mathbf{8 6}$ & $>\mathbf{1 7 8}$ \\
\hline $\begin{array}{c}\text { INSTRUMENTAL } \\
\text { INTENSITY }\end{array}$ & $\mathrm{I}$ & II-III & IV & $\mathbf{V}$ & $\mathbf{V I}$ & $\mathbf{V I I}$ & VIII & IX & $\mathbf{X}+$ \\
\hline
\end{tabular}

Table 4. Calculated factors of safety, and critical acceleration to induce failure with the corresponding earthquake magnitudes.

\begin{tabular}{ccc}
\hline & $\begin{array}{c}\text { Base } \\
\text { conditions }\end{array}$ & $\begin{array}{c}\text { Saturated } \\
\text { conditions }\end{array}$ \\
\hline $\begin{array}{c}\text { Factor of safety } \\
\text { Critical Acceleration (\% of g) } \\
\text { Minimum MMI needed to } \\
\text { induce failure }\end{array}$ & 2.22 & 1.42 \\
\hline
\end{tabular}

\section{Discussion}

The main source of uncertainty that affects both the map and field developed cross-section is the snowpack that was at the site at the time of data collection. The snow was thick enough to cover more nuanced surface features such as surface cracks, ponded water, or smaller gullies. The depth of the snow may have also affected any angles measured with the inclinometer, as at certain points, the person acting as the marker could stand on top of the snow and at a different location would fall through the snow. The second main uncertainty is the location of the water table. While the gully profile is a good estimate, the smallest horizontal separation between the gully and profile was roughly two hundred 
meters. The other estimates should also be reviewed when considering the results. These include the bedrock density, friction angle, and potential failure plane.

It was determined that the landslide was young and inactive as the hummocks were still relatively well defined. There was little evidence for more deeply incised channels and gullies. The inactive determination was supported by the amount of vegetation occupying the headscarp. The Grand Firs and Sword Ferns in the area need relatively deep soil to root in, but it was noted that some bedrock was exposed on the headscarp. The incision of the Nehalem River at the toe of the landslide was also a good indicator of an inactive slide.

The landslide was determined to always be stable when there is no applied acceleration due to the calculated factors of safety. The values are 2.22 for base conditions and 1.42 for saturated conditions (Table 3). However, applying acceleration to the slide can cause failures for both the base and saturated conditions (Table 3). The critical accelerations required to induce the failure, $22 \%$ of $g$ and $7.7 \%$ of $g$, are achievable by the tectonic region that the Oregon Coast Range is located within. These critical accelerations can be related to corresponding an MMI as shown by Worden et al. (2012). The critical accelerations correspond to an MMI of seven and five, respectively. The convergent boundary of the Juan de Fuca plate to the North American Plate is expected to have the capacity to produce earthquakes of an MMI of eight and above.

\section{Conclusion}

From the analysis of the results, it was determined that the deep-seated landslide has a relative age of being young and inactive based on the surface features mapped. The deposit was also determined to be stable in both the base condition and saturated condition. However, the landslide could be reactivated if critical accelerations for the studied conditions are surpassed. This is a very probable scenario due to the tectonic region in which the Oregon Coast Range is located. Understanding one's location and the risks associated with the 
remobilization of landslides can greatly benefit populations across the United States and the world. The potential for mitigating these hazards from an increased awareness of a landslide's potential to fail may be key in protecting those at the highest risks from death and property damage or loss. 


\section{References}

University of Texas, Some useful numbers on the engineering properties of materials (geologic and otherwise) GEOL 615: https://www.jsg.ute xas.edu/tyzhu/files/Some-Useful-Numbers.pdf. Accessed March 2019.

United States Geological Survey, 2.6 Representing macroseismic intensity on maps: https://usgs.github.io/shakemap/manual35/tgintensity.html. Accessed March 2019.

Di, B., Stamatopoulos, C. A., Stavrogiannopoulou, E., Zhang, M., and Bampina, P., 2016, A method predicting the earthquake-induced landslide risk by back analyses of past landslides and its application in the region of the Wenchuan 12/5/2008 earthquake: Nat Hazards, vol. 85, p. 903927, https://doi.org/10.1007/s11069-016-2611-7. Accessed March 2019.

Jesus, C. C., Oliveira, S. C., Sena, C., and Marques, F., Understanding constraints and triggering factors of landslide: regional and local perspectives on a drainage basin: Geosciences, vol. 8, issue 1. https://doi.org/10.3390/geos ciences8010002. Accessed March 2019.

Jibson, R. W., 1993, Predicting earthquake-induced landslide displacements using Newmark's sliding block analysis, Transportation Research Record 1411. Accessed March 2019.

Mirus, B. B., Smith, J. B., and Baum, R. L., 2017, Hydrologic impacts of $\backslash$ landslide disturbances: implications for remobilization and hazard persistence: Water Resources Research, vol. 53, p. 8250 8265, https://doi.org/10.1002/2017wr020842. Accessed March 2019.

Paguican, E. M. R., van Wyk de Vries, B., and Lagmay, A., 2012, Hummocks: how they form and how they evolve in rockslide-debris avalanches https://doi.org/10.1007/s10346-012-0368-y. Accessed March 2019.

Worden, C. B., Gerstenberger, M. C., Rhoades, D. A., \& Wald, D. J. (2012). Probabilistic relationships between ground-motion parameters and modified Mercalli intensity in California. Bulletin of the Seismological Society of America, 102(1), 204-221. https://doi.org/10.1785/0120110156. Accessed March 2019. 